\title{
Which mental model for inclusive cities that are learning
}

\author{
Silvano Tagliagambe*
}

\begin{abstract}
the complex dynamics engendered by distributive asymmetry, climate change, and the effects of mass movement of people and cultures, in the context of transformations informed by processes of shifting and permanency, pose a question of a political and social but also cultural and epistemological nature. The promotion of learning processes focusing on these problems and on pertinent solutions emerges as a central aspect for the construction of a plural and inclusive city and it implies the cognizance of what can be referred to as citizenship. The article discusses a different approach to the crucial concepts of learning, intersubjectivity, and the relationship between our body and the environment of which it is part. The objective is the formulation of a definition of the concept of mind different from those still dominant, which can support new mindfulness of the range of problems affecting urban territories and the type of solution that needs to be adopted.
\end{abstract}

Keywords: Mind, Citizenship, Learning, Transcoding, Cohesion

\section{Premise}

The question of the strategies and activities to undertake in cities to tackle the complex dynamics caused by the effects of mass movement of people and cultures in urban and territorial transformation processes like permanency and shifting, by climate change effects, by the varied and increasingly unfair distribution of wealth and by the outcome of failed development cooperation initiatives is of a political and social but also cultural and epistemological nature.

To manage to encourage and implement the learning processes necessary for the inhabitants of urban territories to acquire effective awareness of the range of abovementioned problems and the type of solution that needs to be adopted, sufficient cognizance is fundamental of what we may call "citizenship". This new mindfulness can only stem from a different definition compared with those still dominant, of the concept of mind, which suggests and requires a different approach to crucial points,

*Correspondence: tagliagambecta@gmail.com

Department of Architecture, Design and Urban Planning, University of Sassari, 07041 Alghero, Italy such as learning, intersubjectivity and the relationship between our body and the environment of which it is part. Only by carrying out the reappraisal proposed, not just of life forms and behaviours, but also of ways of thinking, can we hope to turn our cities into inclusive contexts, open to discussion with the different realities they connect with and capable of expressing innovative forms of interaction between cultures.

\section{Learning from life too, not just books}

Let us begin, then, with learning processes. The reasons for waging a battle to redefine them, so as to make them more appropriate and effective, can be better understood if we highlight the function of hybridisation between culture and life in the development of knowledge, successfully emphasised by a brilliant writer, Jorge Luis Borges, whose way of thinking, not by chance, evades any kind of definition and clears any fence between fields of knowledge. Where he does so with extraordinary efficacy is Averroës' search, a story inspired by a passage in Renan's book on the great philosopher Averroës, in which he says that, though a very intelligent, cultured man, Averroës knew little about the theatre and therefore 
misunderstood, when translating Aristotle, and erroneously defined comedy as satire and tragedy as praise. The following is the crucial passage in Borges' story that describes Averroës grappling "with the monumental work that would justify his efforts to the world: Aristotle's comment. The Greek philosopher was the source of all philosophy and had been given to men to teach them all existing knowledge; to interpret his books, just as the ulema interpret the Koran, was Averroës' difficult aim. History would record few more beautiful and more poetic things than this consecration by an Arab doctor of the thoughts of a man separated from him by fourteen centuries. We must add to the intrinsic difficulties the fact that Averroës did not know Syriac or Greek but worked on the translation of a translation. The previous day two debatable words had held him up at the beginning of the Poetics. They were tragedy and comedy. He had come across them years before, in the third book of Rhetoric: no-one, in the world of Islam, had the faintest idea what they meant. He had flicked through the pages of Alexander of Aphrodisias to no avail, and consulted in vain the versions of the Nestorian Hunain Ibn-Ishaq and of Abn-Bashar Mata. The Poetics text swarmed with those two arcane words: impossible to avoid them. Averroës put down his pen. He told himself (though without much faith) that we usually find what we are looking for close by, then put aside the Tahafut manuscript and went to the shelf where the numerous volumes of the Mohkam by the blind Abensida were lined up, having been copied by Persian calligraphers. One could not imagine he had not consulted them, but he was tempted by the idle pleasure of leafing through their pages. He was distracted from doing so by a strange tune. He looked through the bars of the balcony: some half-naked boys were playing down in the small patio. One, upon another's shoulders, was clearly playing at being the muezzin; with his eyes closed he chanted: "There is no God but Allah!". The one supporting him stood still, being the minaret; a third boy, kneeling in the dust, represented the congregation. The game did not last long; they all wanted to be the muezzin, no-one the congregation or the minaret. Averroës heard them argue in their common dialect, i.e. the primitive Spanish of the common Muslim people of the peninsula".

Busy hunting for the meaning of the two words-tragedy and comedy-of which no-one in the Islamic world had ever heard, Averroës researched it in the books in his rich library, though already fully consulted at length without success. But engrossed as he was in a frantic search to unearth in codified, transmitted knowledge a definition, an explanation in general terms, he neglected the clues the world of the senses had placed before his eyes, from which he would easily have got the answer to the problem tormenting him: the children in the courtyard who, while playing at portraying the muezzin, were on a theatre stage!

However, as Borges himself points out in the conclusion of his tale, this is not the story of an impossible, wrong translation by an Arab thinker about which little or nothing is known. It is the story of Borges himself, it is the perennial issue of the thought: "I felt that Averroës, who wanted to imagine what drama was without knowing what a theatre was, was no more ridiculous than myself wanting to imagine Averroës with no other material but some notes taken from Renan, Lane and Asìn Palacios. When I got to the last page, I felt that my narration was a symbol of the man I was as I wrote, and that, to write it, I had had to be that man, and that, to be that man, I had had to write that story, and so on ad infinitum. (The moment I stop believing in him, Averroës disappears.)".

Borges' Averroës is the story of knowledge that vanishes the moment one stops believing in it, for it does not teach us to see, in life, what books cannot tell us. To stave off this danger we need "knowledge of knowledge", which will be able to explain to us what really deserves to remain oblivious (and why), to achieve that alpha privative that, preceding the name of Lethe, the river of forgetfulness, delivers it to the immortality of what for the Greeks was alètheia, the truth.

\section{Radical uncertainty}

The reasons for this convergence of knowledge and life are highlighted in a book by John Kay and Mervyn King (Kay and King 2020), published in March 2020, which helps us to understand better than any other the problems and challenges science research faces in our times. The two authors, the first of which has taught Economics at the University of Oxford, the London Business School and the London School of Economics and has been a permanent Financial Times contributor for many years, while King was the Governor of the Bank of England from 2003 to 2013, emphasise that most of the situations in our lives now involve radical uncertainty, for which the orderliness of the past does not provide a useful guide to future results. The radical uncertainty they are talking about cannot be described in the probabilistic terms applicable to gambling. It is not just that we do not know what will happen. Often, we do not even know what kind of thing could happen. So we are not referring to the "black swans" mentioned by Taleb (2007) - unexpected events that no-one could have foreseen until they took place, even though such "black swans" are examples of radical uncertainty. We are underlining, the authors write, the vast range of possibilities to be found in the world of improbable events that may nevertheless be described with the help of probability distributions and 
the world of the unimaginable. This is a world of uncertain futures and unforeseeable consequences, over which there is inevitable disagreement, also among experts, that it is difficult to try to solve.

To tackle the unimaginable we have to resort to all the resources of imagination and creativity man possesses: those underlying thought experiments, such as Einstein riding on a beam of light, Schrödinger's cat, and the Einstein-Podolsky-Rosen Paradox, thanks to which it has been possible to propose revolutionary theories like special relativity, general relativity and quantum mechanics, which nowadays are the cornerstones of our knowledge of external reality. To reach the objective of surmounting and "taming" what appears unimaginable through the imagination-one of human fundamental distinctive traits compared with other animals-is a really arduous task that, apart from giving great satisfaction to those able to embark on it, enables science research to make astounding jumps forward in a flash.

The imagination of brilliant minds could not however lead to this progress in knowledge if it did not know how to look at life and the challenges it continually poses and if it were not accompanied and supported by the capacity to overcome the disagreement Kay and King speak of, creating new, more advanced forms of consensus within the community of researchers.

\section{Intersubjectivity as an outcome of the property of "forcing consensus"}

This is the problem that Kuhn (1962) took credit for by focusing on it in his pioneering work of 1962, The structure of scientific revolutions, founded on the notion of "paradigm", the term he used to indicate a set of beliefs not just scientific but also metaphysical, that constitute a theoretical framework where theories may be checked, evaluated and, if necessary, revised. Kuhn's main thesis, in which the paradigm notion plays a central role, is structured around an argument aimed against the conception of change in scientific theories proposed by logical empiricism. For the Vienna Circle exponents, a change in theory is a cumulative process without jolts, in which empirical facts discovered through observation and experiments oblige us to revise our theories, thus contributing to the (ever increasing) knowledge of the world. To this process of revision would be added a process of inter-theoretic reduction enabling us to glimpse, ultimately, the unity of science. Kuhn states that this thesis is incompatible with what really happens, one concrete case after another, in the history of science. Scientific change takes place thanks to "revolutions" in which a preceding paradigm is overturned and replaced by a conceptual picture incompatible or even incommensurable with it. Hence the alleged "facts" of empiricism, that were adopted to support the old theory, become irrelevant for the new one; the questions posed and solved in the new theory are entirely different from those of the old one; indeed, the vocabularies of the two theories in question establish different languages that are not easily intertranslatable. These revolutionary episodes are separated by long periods of "normal science", during which the theories of a certain paradigm are simply refined, better defined and developed. These are sometimes referred to as "puzzle-solving" periods, since the changes have to be understood more on the lines of tinkering with the details of the theories to "save the phenomena" than as steps leading us closer to the knowledge of external reality.

Kuhn thus took his distance from the traditional image of the scientist as a "Galilean" type, conceived as a sort of man in two halves, working along two separate tracks: one of calculation and one of experiment. Both these activities, if carried out according to the rules, benefit from the property of forcing consensus. You don't believe in the results of my calculations? Do them yourself and you'll see you'll inevitably have to agree with me. The same convergence should also be recorded in the case of experiments, if performed as prescribed. They therefore represent, from the Neopositivist viewpoint, the cornerstones capable of producing efficacious discrimination criteria between what is rational and what is not. And they also provide sufficient guarantees of intersubjectivity.

\section{Erosion of the forcing consensus property}

It was indeed the criticism of the "forcing consensus" concept that eroded this image, imposing a radical rerouting of the way of understanding intersubjectivity. As far as concerns direct experience and the experiment, it was Pierre Duhem who had, already at the beginning of the Twentieth century, given the final blow to the idea that this could constitute a straightforward route to building consensus (Duhem 1906). His argument, known as Duhem's thesis, concerned the checking of theories in physical science and is explained with amazing simplicity: "The physicist can never submit an isolated hypothesis for experimental control, but only a whole set of hypotheses. When an experiment contrasts with his forecasts, it teaches him that at least one of the hypotheses making up the whole is unacceptable and must be changed but does not show him which should be changed" (Duhem 1906, p.211). Consequently, any physical hypothesis, taken singly, cannot be falsified by an observational assertion. To be able to do this we must necessarily refer to a wider group of premises, which include:

a. the so-called "initial conditions" and the "basic conditions" of a system, or the set of sentences regarding 
the state of the system observed at the beginning and during observation;

b. the auxiliary hypotheses, namely that set of sentences that in some way allow the language of theory and that of observation to be linked, such as sentences regulating the use of measuring instruments.

A science experiment does not, therefore, consist only of the simple observation of a phenomenon, but also suggests its theoretical interpretation: it is a difficult procedure, in which the results are inextricably tied to theoretical assumptions that are accepted and shared, upon which, consequently, consensus is never forced. When scientists consider a statement disproved, following the negative result of an experiment, they will always and in any case make a choice that does not depend on a logical need, but on various factors like, just to mention some of the most important, their general view of the world and their support of assumptions like realism or conventionalism. When an experiment does not give the expected result, therefore, this fact only says that there is an error somewhere but does not say where. Physics, Duhem says with an effective metaphor, is a machine that does not let itself be taken apart. This means that it constitutes a set of theories, a research programme, an organic whole that is not simply, univocally divisible into good/not good parts due to the result of an experiment.

As far as calculation is concerned, Paolo Zellini recently emphasised that among the strategies to be followed we should not fail to consider: "also that of weakening, at the cost of uncertainty or a tolerable error, the conditions by which a given process of calculation converges on the solution of a problem. These conditions are sometimes not so inflexible and categorical: by weakening them we can succeed in keeping a convergence property, at the same time obtaining indispensable advantages, such as a reduction in algorithmic complexity. The weakening of the conditions then becomes an increase in the power of calculation" (Zellini 2018, p.144).

This strategy is suggested by the need to take into account the growing complexity of the problems to be faced, often entailing working with a large number of variables. It is therefore necessary to develop approximation methodologies that, in any circumstance, lead to algorithms that can be turned into a correct calculation programme, able to be solved on the computer. This transformation requires attention to structure, efficacy, accuracy and reliability. The aspect that interests us here is that in this sphere a crucial role is played by the concept of approximation, and therefore error, considered not negatively as something to be eliminated but as a heuristic resource. Numerical modelling aims to guarantee that the error is small and controllable and to develop efficient resolution algorithms. Controllability is a crucial requisite for a numerical model: numerical analysis provides error estimates that ensure that it is below a precision threshold previously established and considered tolerable.

And things do not end here as, contrary to a widespread illusion, it can happen that even the super-computers available nowadays are incapable of enabling problemsolving, when a problem's complexity grows beyond a certain threshold and proves too great in relation to the role numerical simulation can play. In these cases, reappraisal of the model is required and a reduction in size beneficial. Of course, the adoption of reduced models allows the complexity of the problem to be reduced drastically, making simulations possible that otherwise would not be, but this reduction must be justified. From a physical point of view, it should not make the problem under inspection lose significance, while from the mathematical viewpoint it should maintain the fundamental theoretical properties of the original model. The synthesis between these two requirements is not always simple and anyway requires a choice, so it is not possible to speak of a simple mechanism of forcing consensus, from which a means of access could be triggered that is non-problematic for the intersubjectivity suggested.

\section{The process of building consensus and intersubjectivity}

Consensus therefore has to be developed, step by step, following a precise method; not by chance these days, do we tend to speak, with Derrick De Kerckhove, of "connective intelligence" in the network and social society (De Kerckhove 1998, 2001).

According to the definition he supplies, this type of intelligence is a form of connection and collaboration between various individual and collective subjects that is the result of sharing, developed on the basis not of force, but of a dialogical exchange. The characteristic trait of this way of thinking that distinguishes it from those coming under "collective intelligence" is that-in contrast with what usually happens in the latter-in connective intelligence each single individual or group keeps its own specific identity though being part of a structure that is much more articulate and far-reaching in its links. We are therefore faced with a process of exteriorisation of intelligence, which becomes a process supported and revealed by the network.

Hence, the connective form of intelligence is one determined by the relations of single agents and it can (and usually does) produce learning and innovation, improving the skills and performance not only of the system as a whole but also of the single parts belonging to it. What it makes clear is the increasing rate of a tie or intersection 
expressed by the preposition between, not however made to pass as universal. The traits many individuals have in common are universal: being based on copulation may lead to something universal in this sense, namely traits present in all single individuals, as in the case of collective intelligence. Whereas what is common is that which exists and is built up in the relationship between individuals, which does not exist tangibly in any individual taken singly, but only abstractedly in the relationship between many individuals. Connective intelligence exists only in this relationship, and none of the members involved in it may claim it and attribute it to themselves entirely, in that it is literally a case of something supra-personal and impersonal, trans-individual.

The importance and topicality of these concepts are also confirmed by the development within the sphere of formal logics of systemic theories for multi-agent systems-formally multimodal systems, that can also incorporate a time dimension-which envisage the possibility for each agent to reason on their knowledge and that of others and enable the identification of distributed or common knowledge (Fagin et al. 2003).

Thus, the guiding idea emerges that is the main theme of the cultural approach proposed: an "owner" of truth does not exist; if we want to define what we call "owner", it is the result of a collective process born of the comparison between experts, who are brought together to talk productively with the aim of generating information responding to a specific argument or problem via a structured discussion between them. The explicit intention is to go beyond reciprocal incomprehension and limit the differences, seeking points of balance. In the situation of uncertainty, so successfully described by John Kay and Mervyn King, the only satisfactory response that can be provided and appears able to overcome the scrutiny of rigorous critical thought is to cross the limit of each one's view and manage, through dialogue, to choose which themes among them all the various skills and knowledge converge on. Then it is reasonable to call the result of this selection "consensus" and make it the base, the only one we can rightfully use-in the absence of a satisfactory database supporting the decisions to be made-for the intersubjectivity construction process. The problem then becomes to identify the methodologies that may lead in the most reliable way possible to the structured development of consensus between a group of experts in the analysis and study of a complex argument.

\section{The dual nature of the body and the observer/ observed relationship}

When a child touches the parts of its own body it experiences the two complementary sensations of touching and being touched and it is precisely upon these twin impressions-a subject being simultaneously the object of its action-and the kind of glance triggered, that reflexivity, sensorial and mental, gradually develops. Awareness is therefore reached of the dual nature of our body, shared between an observing subject and agent and an observed object that is acted on. Its total identity moves into a border territory, an intermediate space between inside and out, in which the boundary between 'external' and 'internal' becomes so porous as to nullify conventional distance.

Anzieu (1995) concentrated on the function and fundamental importance of the skin, highlighting, in particular, the vital role this "boundary" of our body has in containing psychic material and emotions, based on the awareness of a surface that guarantees the possibility of differentiating internal from external space. In his opinion there are two fundamental biological parts in human beings, skin and brain. These are formed in the ectoderm. In other words, the cerebral cortex and the skin are as important as the centre and the outskirts of a metropolis. Thus, the nervous system is formed: the I is not born in the centre but the outskirts. And it is in the skin that the affectionate reactions of a body originate; the first sensation of the I is epidermal. This conceptualisation defines the body as a complex system, linked with double feedback, sensorial and cognitive.

From this point of view the internal and external spaces may be considered two wrappers which vary depending on the individual and the circumstances: the arousal wrapper and that of communication or significance. The child's mental apparatus acquires an $I$ when this topographic structure with a double wrapper begins to emerge.

Through its external part this type of structure puts the subject into direct contact both with the environment, its structures and dynamics, and with colours and sounds, scenarios, atmospheres and situations, profiles and shapes, including other people. This is why affection and the emotions that are grafted and grow on this contact and on the resulting relational fabric involve space as well, apart from the living organisms, and therefore include the transmission of the states of mind produced in a place based on its intrinsic features and the type of bond that is established with those inhabiting or observing it, "putting themselves" in its place. From this intermingling of spatial forms and situations and the expressive tones they exhibit, a dynamic form of interactive "resonance" springs: internally, as a result of the impressions sparked by the harmony between the structure of the space and its atmosphere, a sympathetic vibration starts up and expressivity that are projected outwards, granting the place constantly new connotations, symbolic forms and values, which reflect those of 
the internal universe. In this case, to become aroused, therefore also means to start up internal kinematics in this internal world, which, through the external wrapper, enters into contact and relations with the other physical components of the environment in which one is immersed and which, in turn, becomes retroactive, in the opposite direction, on the internal body, upon which it leaves traces that have an effect, imprints that model and configure its sensations and states.

The body therefore intrinsically appears to be double on the inside, in that it is simultaneously subject and object; a subject that springs from the object and takes the latter on as a "target" of its glance and description. The resulting image - thanks indeed to the placing of personal identity as no longer only and fully part of one of the two components in question, in this case the observing subject, but, as we said, in the intermediate space and interface between them-does not appear as the product of simple communication and exchange of information, or a one-way knowledge process. It becomes instead the result of a sort of kolv $\omega v i \alpha$, which is union and participation, and therefore reciprocal involvement.

This division and dual nature of the body, thanks to which it appears on the one hand subjected to perception and cognition, and therefore intrinsically tied to the subject, and on the other an external body, to be treated as we treat all other objects of the external reality surrounding us, means that the tripartition brain-body-environment should really become a quadripartition brain-body interior-body exterior-environment, where the external body is a permeable, porous boundary, an interface that links the internal body with the environment, an element of separation and at the same time of connection between the two.

That being so, it is stressed that two alternative, quite different models exist to describe and explain the relationship between the brain and the environment:

- for classical physics, they are two separable areas, endowed with given, designated properties that make up their specific physical reality and which reciprocally change each other (ontology of property) when they enter into a relationship. The principle of locality is applicable;

- for quantum physics, however, a physical system like the brain is manifest only and always interacting with another, in this case the environment, and vice versa, so the description of one is always given with respect to the other (ontology of relations). In this second case any description of the state of the brain is thus a description of the information it has of the environment, i.e. of the correlation between the two systems: the brain is therefore considered an open, dissipative system, whose functions do not exist except when interacting with the environment. The principle of non-locality is applicable.

Quantum models of the brain, which follow this second model, are thus initiated by the two following assumptions:

- any description of the state of the brain is a description of the information it has of the environment, namely of the correlation between the two systems;

- this information the brain has on the environment affects what the brain is like.

On the grounds of these premises Ricciardi and Umezawa proposed a quantum model of the brain in 1967 using quantum field theory (QFT), which describes, providing experimentally confirmed results, the advent of ordering systems such as crystals, ferromagnets and superconductors. This therefore fits within the scenario of 'many body' quantum field theory that effectively explains the appearance of coherent collective behaviours based on a number of 'elementary particles', and is commonly used, for example, in condensed matter physics.

Freeman and Vitiello $(2008,2016)$ recently proposed their dissipative quantum model of the brain as an extension of that of Ricciardi and Umezawa. It is a model in which the neurons and other cells are not considered quantum components, unlike in other quantum models of the brain present in the literature. This envisages that the external stimulation to which the brain is exposed leads to a spontaneous rupture of its symmetry, but the ordered structure that will form will depend on the internal dynamics of the brain. It is indeed the prevalence of the internal field of signal "decoding" that entails the possibility that a certain memory be evoked by completely different stimuli from the one that induced memorisation, and in conditions partly or entirely different from those it was in when the memory was retained.

\section{Quantum entanglement and the brain/ environment relationship}

The aspect of this model that interests us here is that it considers the brain an intrinsically open system, permanently coupled with the external environment and leads to the image of a mind that lives by means of a continuous series of phase transitions and thus of new emerging levels. This coupling postulates that between the brain and the environment a reciprocal mirroring relation is established which traces the one between an object, a body, a face and its specular image. In these cases what, or who, is reflected, mostly passively, and the result of this are two constants that, in the simplest case, exactly 
match each other. They cannot overlap, however, as they are linked by the property that Lord Kelvin called chiralità in 1904 (from the Greek xeíp, "hand"): namely, a rigid object (or spatial device of points or atoms) cannot overlap its specular image, such as the right hand with respect to the left, and vice versa. In the same way we could say that the environment is the specular image, and therefore the double, of the structure and functioning of the brain, since in their relationship, which constitutes a closed system, what is incoming for the environment is outgoing for the brain, and vice versa. The brain and the environment, from this point of view, behave in exactly the same way as long as the direction of the flows is reversed. Since, technically, this direction is reversed by changing the sign of the time variable, we may say that the system describing the environment behaves like a copy of that describing the brain for which the time direction has been reverted: it is thus the time-reversed copy of the latter. To summarise, the system that describes the environment, as far as concerns balancing the energy flow of the system describing the brain, is also its time mirror image: let us briefly express this fact by saying that the system that describes the environment is the Double of the system describing the brain.

Entanglement or 'intrication', the intertwining of the brain and its environment, an extension of entanglement as quantum effect, is therefore described as a permanent coupling, or a dynamic dialogue between the two, from which in Freemann and Vitiello's model perception emerges, appearing however as a highly dynamic process rooted in the dissipative nature of cerebral dynamics, i.e. in the thermodynamics of non-balance of its metabolic activity (Freeman and Vitiello 2008, 2016).

Before going ahead, it is worth briefly dwelling on what entanglement is from the point of view of quantum physics and the possible applications of its logics in our discussion. If Heisenberg's uncertainty principle expressed in 1927 is applied, two conjugate variables of a system cannot be known simultaneously and with the same arbitrary precision: for example, the position and quantity of movement of a particle. Processes exist in nature, however-such as some processes linked with the decay of subatomic particles-thanks to which it is possible to produce two particles that are identical but endowed with opposite speed; they therefore move in a specular way with each other. "In this pair of particles it is possible to think, ideally, of measuring the two conjugate variables separately. For example, the position, with extreme precision, for the first particle and the speed, still with extreme precision, for the second. Given that the two particles have opposite positions and speed, knowledge of both the position and the speed of the first entails knowledge of the position and speed of the second. Given the initial considerations, this is so, with the same precision. Now, considering that in the case in point, both the position and the speed have been measured accurately, we are able to simultaneously know both conjugate variables of each particle, in open but only apparent contradiction with what Heisenberg's uncertainty principle states" (Fracas 2017, p. 165). In effect, given that the two particles are correlated, they constitute a single system: "if we measure the quantity of motion of a particle, the quantity of motion of the other one is also determined. By doing this, however, the position of the first particle is altered and consequently also the position of the second particle. In any case, the system is disturbed. Hence, when we measure the position of the second particle, the measurement is taken in a system already altered" (Fracas 2017, p. 166167). It being a single system, defined as entanglement of the two particles, Heisenberg's uncertainty principle maintains its own validity unchanged.

\section{The mind in the light of the logic of an entangled system}

By applying single-system-entangled system-logic to the brain-environment pair, it follows that we cannot speak generically of environment but need to refer to that specific environment that is constantly structurally coupled with our brain, to the point of needing to be conceived and described as its 'double'. Consequently, what we call "mind" actually proves not to be something that happens inside us, within our skull, but a complex, dynamic, open process stemming from the co-existence and co-evolution of the body-brain system with the environment-world and vice versa. This is in line with the statement of the need, highlighted in his times by Popper, "to take the 'mind' not as the seat of psychophysiological processes or a theatre in which beliefs, desires and emotions mingle, but as a production agent of knowledge and theories, not individual and subjective therefore, but indeed fact-based. Precisely for this reason its independence from the brain should be firmly stated and safeguarded: "what might be called the second world-the world of the mind-becomes more and more, at a human level, the connecting link between the first and third worlds: all our actions in the first world are affected by the way we grasp the third world by means of our second world" (Popper 1972, p.207). The mind is therefore "a typical border situation, an 'interface' between two radically different worlds, the first physical, that of external reality, and the third, that of knowledge in all its manifestations, to be studied as an organ of adaptation, thus from the point of view of its adaptive function and its products, and not only or not so much, from the viewpoint of the processes carried out therein. A different evaluation of intentionality arises that can no longer be 
considered brain secretion (according to Searle), being its original, intrinsic attribute, nor an attribute and product of the psychic processes, as an original 'language of thought' proposed by Fodor. It is instead what anchors subjectivity to the third world of fact-based knowledge and makes rationality emerge not as a mental attribute but as an objective value tied to our relationship with the environment and the capacity of mental processes to grasp its structural features and the principles that regulate its dynamics" (Tagliagambe 1997, p. 207).

This is an aspect that is taking on great importance in the analysis of the relation between the normal and the pathological; on these grounds we can say that in the model we are considering the conscious processes surface from the continuous dialogue between the system and its Double, as defined above, and that these could consequently be described as a special property of autointeraction of the system with itself. We can then apply to psychology and diseases of the mind the aspect Georges Canguilhem considered crucial in his essay $\mathrm{On}$ the normal and the pathological, written partly in 1943 and partly during the period 1963-1966: "The living and the environment are not normal if taken separately, but it is their relationship that makes them the one and the other" (Canguilhem 1998, p. 113). This means that the origin of notions of health and illness is to be sought in the experience men have of their relations overall with the environment, so that the models of the brain taken into consideration here become extremely significant and important also as far as medical science and psychology are concerned.

\section{Conclusion}

These are the assumptions and conditions, in my opinion, upon which the city can effectively become an inclusive context, open to dialogue and capable of handling the challenge of integration of differences and conflicts that distinguish its social composition. To win this challenge we need to accept that the city experiences (and suffers from) contrasting requirements, demands, functions and interests that stand as antithetical and mutually exclusive. The gamble inherent in this challenge is faith in the social city's capacity to mediate and gradually find new harmonies, becoming a place where information is "transcoded" (Camagni 2003, p. 95).

This last concept is particularly important, in that it indicates the fact that "shared vision is not a project achieved on the drawing-board, even less by bright, paternalistic technocrats, but a social construction that proves valid only if crossed with the wealth of interactions, experiments and planning of the sector. So in strategic planning, the vision appears logically as an assumption and historically as the result of the entire process of metropolitan governance" (Donolo 2003, p. 111).

For these aspects transcoding, which takes the city as an expression of difference and plurality of the variety of voices inhabiting it and firmly asserts the need for convergence to succeed in emerging from these voices and their encounter/clash-or at least a balance making it possible to live together, averting the temptation the various voices have to disagree and cancel each other out-is diametrically opposite what we might call "Utopian logics". In the different forms and expressions in which the latter is manifest, not by chance is the gift of languages present, but never the translator. This is symptomatic, in that it is only on the basis of translation problems that the possibility may be imagined and realised of "really letting oneself be inhabited by various languages", as Walter Benjamin emphasises in an essay entitled The translator's task (included in his translation of Baudelaire's Tableaux Parisiens) (Benjamin 2006), respecting differences so as not to "compress" their multiplicity and the internal complexity of each one and not reduce the dignity of the varied, different voices under a form of tolerance that risks ending up as assimilation. Transcoding logic may, and must, therefore be seen as a sort of overturning of Utopian logic. The inhabitants of the latter believe they are carriers of the only possible, successful perspective, the only way to understand the world and its enigmas. They are therefore oriented towards the assimilation of other cultures, rather than actually understanding them (Aresu 2006).

To acquire this information-transcoding function at a local level and its convergence towards a package of considerations, values and objectives able to become the cornerstones of a shared background for its future development, means, for the city, being available and equipping itself, via an approach integrated with the management of the complex relations that exist between economic, social, cultural and environmental dynamics, to tackle the issues of strategic positioning in the context of world economics. It also means to acquire a new way of seeing itself and seeing the world, in which problems are not caused by isolated events but by systemic interdependencies that need to be recognised to develop organisational architecture founded on guiding ideas and values that are in some way convergent.

Transcoding is the necessary prerequisite of cohesion, i.e. achieving that value that rests on recognition of the fact "that the city is built of economic and cultural differences, residential and occupational circumstances and changing periods of time that often overlap and interweave; it is also full of diversified social diseases, chronic grievances, bitterness, hostility between groups forced to interact in necessarily shared spaces". In this situation, to 
aim at cohesion means to understand that "differences can develop towards polarisation between incompatibles or be appreciated and improved as a resource of a plural city that can guarantee basic needs for all and-if it still does not succeed-that will work to mend the lacerated edges, recuperate marginal places and constantly reconnect centre and outskirts" (Aresu 2006, p. 112). Hence the "border that takes shape" and materialises in this work of repairing the edges, guided by the conviction that "a city without cohesion is ugly, dirty, bad and becomes unliveable even for the privileged; it also becomes inefficient and unproductive. A cohesive citywhich is on the virtuous path of cohesion as a permanent commitment-is enriched with possibilities, much more open to the global and diverse, it is the right city, it enjoys proper importance" (Aresu 2006, p. 112). It is nevertheless worth reiterating once more that "sharing has nothing to do with unanimity, but with working out the differences and building a plural society. [...] Conflict must be turned into negotiation and this should not be a partitioning compromise but the learning of better preferences and abandoning of bad habits. For this, places, moments, communication and databases are needed for deciding, formalising alternatives and assessing. We must manage to recognise that many opposing interests are legitimately present in the city and also different cultural ways of using the city, which need to find time and space to strike a proper balance. No city is single-voiced, but each has more than one vocation and potential. There must be recognition and recognisability for all" (Aresu 2006, p. 114).

Even though cohesion is recognition and enhancement of differences and does not entail uniformity or, even less, standardisation, it is nevertheless diametrically opposite the widespread tendencies towards urban sprawl, with no limits or internal coherence, caused by the "growing double speed of the city evident both in the thick fibre of metropolises, where central or pericentral districts enhanced by large projects for replacing functions contrast with edge districts, abandoned to progressive economic, social and environmental decay; both on periurban territory, more and more characterised by "spirits of excellence" and "spirits of decline". In both cases the choices local authorities make, in the absence of shared reference frames defined at a supra-local level, have often privileged highly selective public/private interaction practices, and have been prevalently conditioned by property market inclinations and expectations" (Gibelli 2003, p. 57).

These tendencies must be countered by redevelopment planning based on the acknowledgement of important shared objectives and the consequent definition of "strategic axes" regarding the city and surrounding territory and targeting a rise in urban quality level. This type of project development has little to do with the "beautiful projects" or "great projects" which we increasingly entrust as "showpieces" to respond to the great need to improve a city's image and competitive positioning. In the best cases these do in fact please the eye, whereas the project development we are referring to is the result of "a discussion session «inclusive» of the collective imagination and aimed at building up alternative qualitative scenarios, picking out the important objectives and main lines of strength of the planning action coherent with them and assessing the possible outcomes from the start" (Gibelli 2003, p. 57).

\section{Acknowledgements}

Not applicable.

\section{Authors' contributions}

The author read and approved the final manuscript.

Funding

Not applicable.

Availability of data and materials

Not applicable.

\section{Declarations}

Competing interests

The author declares no competing interests.

Received: 13 December 2021 Accepted: 13 January 2022

Published online: 04 February 2022

\section{References}

Anzieu D (1995) Le moi-peau. Dunod, Malakoff. Italian edition: Anzieu D (2017) L'io pelle. Raffaello Cortina, Milan

Aresu A (2006) Filosofia della navigazione. Bompiani, Milan

Benjamin W (2006) Il compito del traduttore. In: Solmi R (ed) Angelus novus Saggi e frammenti. Einaudi, Turin

Camagni R (2003) Piano Strategico, capitale relazionale e community governance. In Pugliese T, Spaziante A (eds) Pianificazione strategica per le città: riflessioni dalle pratiche. Franco Angeli, Milan

Canguilhem G (1966) Le normal et le pathologique, Presses Universitaires de France, Paris. Italian edition: Canguilhem G (1998) II normale e il patologico. (Porro M, Foucault M eds) Einaudi, Turin

Donolo C (2003) Partecipazione e produzione di una visione condivisa. In: Pugliese T, Spaziante A (eds) Pianificazione strategica per le città: riflessioni dalle pratiche. Franco Angeli, Milan

Duhem P (1906) La théorie physique: son objet et sa structure. Marcel Rivière, Paris, France; Italian edition: Duhem P (1978) La teoria fisica: il suo oggetto e la sua struttura (trans: Petruccioli S). II Mulino, Bologna

Fagin R, Moses Y, Halpern JY, Vardi MY (2003) Reasoning about knowledge. MIT, Cambridge

Fracas F (2017) II mondo secondo la Fisica Quantistica. Sperling \& Kupfer, Milan

Freeman WJ, Vitiello G (2008) Dissipation and spontaneous symmetry breaking in brain dynamics. J Phys a: Math Theoretical 41(30):304042

Freeman WJ, Vitiello G (2016) Matter and Mind are entangled in two streams of images that guide behavior and inform the subject through awareness. Mind and Matter 14(1):7-24

Gibelli M C (2003) Flessibilità e regole nella pianificazione strategica: buone pratiche alla prova in ambito internazionale. In: Pugliese T, Spaziante A (eds) Pianificazione strategica per le città: riflessioni dalle pratiche. Franco Angeli, Milan 
Kay J, King M (2020) Radical Uncertainty: Decision-Making Beyond the Numbers. W.W. Norton \& Co, New York

Kerckhove De (1998) Connected intelligence: the arrival of the Web society. Kogan Page, London

Kerckhove De (2001) The architecture of intelligence. Birkhäuser, Basle-Boston Kuhn TS (1962) The structure of scientific revolutions. University of Chicago

Press, Chicago, Italian edition: Kuhn TS (1969) La struttura delle rivoluzioni scientifiche. Einaudi, Turin

Popper KR (1972) Objective Knowledge: An Evolutionary Approach, Oxford University Press, London. Italian edition: Popper KR (1975) Conoscenza oggettiva. Un punto di vista evoluzionistico. Armando Editore, Rome Tagliagambe S (1997) Epistemologia del confine. II Saggiatore, Milan Taleb NN (2007) The Black Swan. Random House and Penguin Books, New York. Italian edition: Taleb NN (2008) II Cigno nero. Come l'improbabile governa la nostra vita. II Saggiatore, Milan

Zellini P (2018) La dittatura del calcolo. Adelphi, Milan

\section{Publisher's Note}

Springer Nature remains neutral with regard to jurisdictional claims in published maps and institutional affiliations.

\section{Submit your manuscript to a SpringerOpen ${ }^{\circ}$ journal and benefit from:}

- Convenient online submission

- Rigorous peer review

- Open access: articles freely available online

- High visibility within the field

- Retaining the copyright to your article

Submit your next manuscript at $\boldsymbol{\nabla}$ springeropen.com 